\title{
Investigation of Joints in 3d Spacer Fabric Composites
}

\author{
Vishnupriya Nair ${ }^{\dot{A}^{*}}$,Anil Kumar. $\mathrm{V}^{\dot{B}}$ and S.Naresh Kumar ${ }^{\dot{C}}$ \\ ${ }^{\dot{A}}$ Aeronautical Engineering,Hindustan University, Chennai, India. \\ ${ }^{\dot{B}}$ Aeronautical Department, Vardhaman College of Engineering, Shamshabad, India. \\ ${ }^{\mathrm{C}}$ Mechanical Department, Vardhaman College of Engineering, Shamshabad, India
}

Accepted 10 January 2014, Available online 01 February 2014, Special Issue-2, (February 2014)

\begin{abstract}
Airframe applications of composite material structures have been investigated for a number of years. With the availability of advanced fibrous reinforcements of high specific strengths and moduli, airframe weight reductions of about 40 percent were frequently predicted. However, as actual development programs were completed it became apparent that weight savings from increased strength and stiffness could be easily offset by weight losses resulting from inefficient joining of these materials. Eliminating structural joints and cutouts (which are special joint cases if stressed covers are used) is impractical in present-day aircraft because of the requirements for manufacturing breaks, assembly and equipment access, and replacement of damaged structures. Optimum joint proportions have evolved from essentially invariant relationships between tension, shear, and bearing strengths (and moduli) of structural metals. Because of the fundamental differences in properties caused by the anisotropy and inhomogeneity of composites, design policies that were evolved for metal joints cannot be applied directly to composites. The basic strength and modulus relationships on which metal joint technology is based are variables in the composite structural design process. Thus, the design of optimum joints in reinforced composites must start in the selection and arrangement of the basic material constituents.

The objective of this project is to create a $3 D$ spacer fabric composite by simple hand layup technique and conduct mechanical tests on them by joining them in different methods. Thus, to find the joint that gives the highest strength. Also, to evaluate the failure modes of the specimens and predict the best joint configuration for the material under consideration. Three methods are followed for achieving viz. Mathematical method, Analytical Method and Experimental Method.
\end{abstract}

Keywords: Design, Joints, Composite Materials.

\section{Introduction}

Composite materials present a unique opportunity to engineer a material in order to optimize its physical, thermal and mechanical properties for specific applications while offering many advantages such a relatively high specific strength, stiffness, fatigue resistance and corrosion resistance with respect to weight. Due to their exceptional qualities, composites can be found in manyapplications, from aircrafts, helicopters and spacecrafts to submarines, automobiles and sporting goods.

Many prospects have been investigated as methods for improving these characteristics, however composites reinforced with $3 \mathrm{D}$ fabric architectures appear to be the most promising solution. Here an investigation of $3 \mathrm{D}$ fabric architectures, manufacturing methods, and composite properties are reviewed in order to have better understanding of the pros and cons of such a material as well as potential improvements and opportunities. As expected 3D composites solve many of the problems faced by $2 \mathrm{D}$ composites, however these improvements are accompanied by the deterioration of in plane properties Many 3Dcomposites show potential for applications unsuitable for 2D composites, however optimization of 3D fabric manufacturing, composite production, andapplication needs further investigation.

\subsection{Mechanical Characteristics}

Parametric study conducted over a range of structurally possible geometrical parameters shows that performance of a material depends on factors like braiding angle, yarn aspect ratio and gap.(Aggrawal, et al,2001). The mechanical properties of the knitted composites with respect to architecture and knit/structural parameters are broadly related to the state of the micro structural imperfections, viz. fiber bending and fibrecrossover junctions, and also to the relative fibre distribution along the two principal loading axes, in the knit structure. (Khondker and Leong,2001).The mechanical performances of monospacer fabric composites can be widely adapted to the respective requirements through the choice of the structural factors. (Min Li, et al,2008) 
Low-stress mechanical properties obtained by the KESfabric evaluation system revealed that all tensile, bending and compression properties of spacer fabrics are greatly fabric composite with integrated hollow core has been developed.

Low-stress mechanical properties obtained by the KES-fabric evaluation system revealed that all tensile, bending and compression properties of spacer fabrics are greatly depending on the type of spacer fabric, the type of spacer yarn used, the yarn count of the spacer yarn, the stitch density and the spacer yarn configuration. Air permeability and thermal conductivity of spacer fabric are closely related to the fabric density.(Sun Pui $\mathrm{Ng}$ and Yip,2008)

The 3D spacer fabrics have super-high specific strength and specific stiffness that additional weaves could strengthen the composite face sheets greatly, and the multi-face sheet structure could improve the properties correlated with the piles effectively.(Wang, et al, 2009).

The bending stiffness of flatwise specimens converges to that of the edgewise specimens with increasing laminations and the specimens in the edgewise position failed with greater ductility due to progressive failure of the fibre composite skins while the specimens in the flat wise position failed in a brittle manner due to debonding between the skin and core.(A.C. Manalo, et al, 2010)

The type of knitted structure significantly influences the mechanical performance of the 3D stitched wovenknitted composites. The composite using interlock structure as the inner layers has the best results concerning energy absorption and tensile strength. The varied plain knit structure provides the highest Young's modulus among knit, 1_1 rib, Milano, and interlock stitches.(Zhang, et al, 2010).The 3D textile composites have resin crack and fiber breakage under quasi-static indentation tests while only elasto-plastic deformation has been found in aluminum. The energy absorption of the 3 Dtextile composite is greater than aluminum.(Hong $\mathrm{Hu}$,et al, 2010).

The mechanical properties of mono spacer fabric composites cannot meet the demand ofstructure application because of the thin facesheet and low loadbearing capacity of high piles. But additional weaves reinforcement can enhance edgewise compressive and flexural properties effectively. Foam filling is one of the best options to improve the flatwise compressive and shear properties. (Shaokai Wang, et al, 2010).

Due to inferior mechanical properties, such as elasticity and deformability under applied loads, conventional spacer fabrics are not suitable for high performance composite applications. One solution is to connect the planes by means of fabric layers instead of pile yarns. (FakultatMaschinenwesen,2010)

\subsection{Joint Analysis}

In the adhesive joints, the tensile modulus decreases progressively with increasing temperature. Shear modulus also varies with changing room temperature, but is restored when temperature becomes normal.(Edward, et al, 1968).In terms of weight efficiency, bonded joints are superior to bolted joints, reducing the weight penalty by one order of magnitude. Improved strength can be obtained using an adhesive that exhibited considerable ductility. The of combination bolted/bonded joint performs well under both static and fatigue load conditions. The presence of the bolt enhances the performance of thebond, and vice versa. (Lehman and Hawley, 1969).

Adhesive bonding is a viable technique for joining composite materials though the low inter laminar shear and tensile strength limit the joint efficiency. Suitable surface treatments and adhesives for a given application have to be chosen.(M D Banea and L F M da Silva,2008).

\subsection{Failure}

The formulation of J-integral issued in a coarsely meshed finite element analysis that bypasses strain singularity and inelastic behavior at crack tip while studying the mixed mode fracture characterization of adhesive joints on the basis of J-integral using double cantilever beams and single lap joint specimen. (Weerts and Kossira ,2000).

A three-dimensional woven composite strength model is analyzed and presented for predicting the failure behavior of three-dimensional angle interlock woven composites under on-axis uniaxial static tensile loading and shear loading. The model predicts the stress levels at which the secondary failures take place a sub-elemental level.(N.K.Naik, et al, 2002).

FRANC2D a software package predicts the failure initiation load using mixed mode fracture toughness data of adhesively bonded composites specimens. FRANC2D is used to model and analyse single lap joint model to generate load vs strain energy rate release curves. The fracture toughness and critical strain energy rates were obtained in this method.(Suranga Gunavardhana,2005).

\subsection{Application \& Advancements}

A high Vfwas a key driver in delivering improved fracture toughness and with superior yarn and textile design a better overall balance of stiffness, strength and fracture toughness is achievable. Flax composites demonstrate a robust yarn that resists deformation but requires a higher density preform if performance is to improve.(J.A.Soden, et al, 2000).Various wide application in the industry for 3D Spacer Fabricsare attained by advanced knitting technologies.(Shanna M Bruer ,2005).

Spacer fabrics present special advantages in the composite structures as are inforcement and filler material.(Mecit and Marmarali, 2012).Composites having only spacer fabrics have lower bending strength. However, spacer fabrics present different advantages as filler materials for composites. As a result, spacer fabrics can be an alternative filler material in terms of bending strength in composites.

\section{Research Methodology}

The method of progression and approach to the paper is given below: 


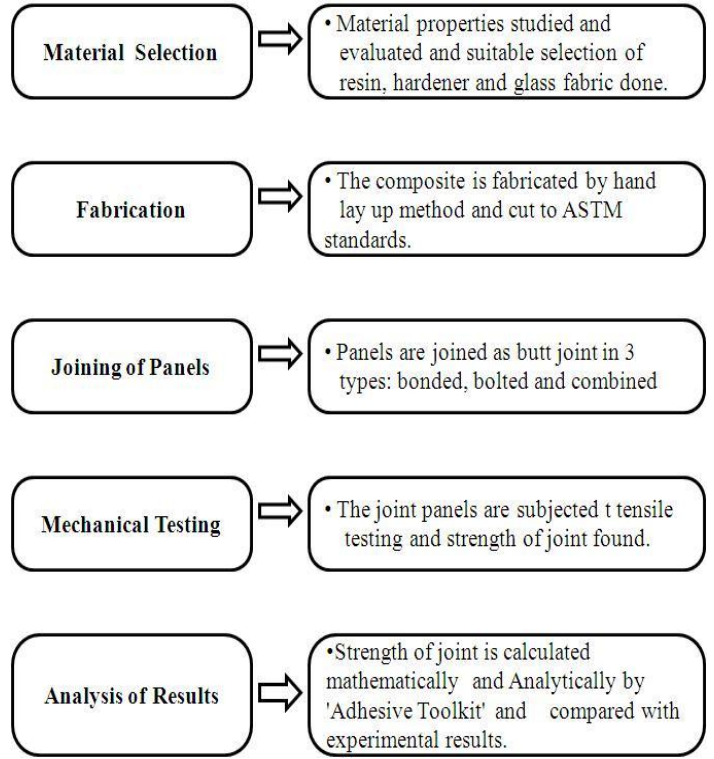

Fig. 2.1 Research Methodology

\subsection{Material Selection}

The materials selection is an intricate process wherein properties of arrange of materials are examined to select the suitable material required for the fabrication of the $3 \mathrm{D}$ spacer fabric composite. The properties of a wide range of resins, hardeners and glass fiber fabrics are discussed in the following sections.

\subsection{Glass Fiber Cloth}

Fiberglass fabric is a flexible mesh made from spun-glass fibers that are woven into a pliable, cloth-like material. It is available in rolls or sheets. Fiberglass fabric is rarely used alone. Fiberglass is a lightweight, versatile, and costeffective material used in an endless variety of industrial and commercial products. Fiber glass mesh fabric is used extensively in shipbuilding and air craft construction. It provides a framework to which a liquid resin is bonded, providing strength, form and durability to the end product. At present there are five major types of glass used to make fibers.

- A-glass

- C-glass

- E-glass

- S-glass

- D-glass

The most commonly used cloth all over the world is Fiber Cloth E making it the mostly easily available glass fabric in the market which is selected for the experiments.

\subsection{An Overview of Resins}

The factors to be considered while choosing a resin for joining composite materials are:

\section{i. Adhesive Properties}
ii. Mechanical Properties
iii. Micro-Cracking resistance
iv. Fatigue Resistance
v. Degradation from Water Ingress

Given below are few popular resins from the wide range of resins available in the market along with their properties. This would give an insight into the various adhesive types, their properties and applications and which will help in choosing the appropriate resin for the material under consideration.

Table 2.1 Resins and their properties

\begin{tabular}{|c|c|c|c|}
\hline S.No & Resin & Rating & $\begin{array}{l}\text { Preferred } \\
\text { Material }\end{array}$ \\
\hline 1 & $\begin{array}{l}\text { Toughened } \\
\text { Acrylics }\end{array}$ & Structural & $\begin{array}{l}\text { Plastics and } \\
\text { metals }\end{array}$ \\
\hline 2 & Anaerobics & Sealant/ Structural & Metals \\
\hline 3 & $\begin{array}{l}\text { Cyanoacryl- } \\
\text { ates }\end{array}$ & $\begin{array}{l}\text { Structural ( small } \\
\text { parts })\end{array}$ & $\begin{array}{l}\text { Non porous } \\
\text { materials, } \\
\text { plastics and } \\
\text { rubber }\end{array}$ \\
\hline 4 & Epoxy & Structural & $\begin{array}{l}\text { Plastics and } \\
\text { Metals }\end{array}$ \\
\hline 5 & $\begin{array}{l}\text { Hot-melt } \\
\text { Adhesives }\end{array}$ & Semi/Non structural & $\begin{array}{l}\text { Wide } \\
\text { ranging }\end{array}$ \\
\hline 6 & Polyuretha-nes & $\begin{array}{lr}\begin{array}{l}\text { Structural } \\
\text { modulus, } \\
\text { systems }\end{array} & \begin{array}{r}\text { lower } \\
\text { tough }\end{array} \\
\end{array}$ & $\begin{array}{l}\text { Plastics and } \\
\text { metals }\end{array}$ \\
\hline 7 & Silicones & Sealant/Structural & Glass. \\
\hline 8 & PVA adhesives & Semi-structural & $\begin{array}{l}\text { Wood and } \\
\text { board }\end{array}$ \\
\hline 9 & $\begin{array}{l}\text { Amino or urea } \\
\text { based } \\
\text { adhesives }\end{array}$ & Structural & $\begin{array}{l}\text { Interior } \\
\text { wood. }\end{array}$ \\
\hline 10 & $\begin{array}{l}\text { Phenolics and } \\
\text { Resorcinolic } \\
\text { adhesives }\end{array}$ & $\begin{array}{l}\text { Structural (have } \\
\text { shock susceptibility). }\end{array}$ & $\begin{array}{l}\text { Metals and } \\
\text { wood }\end{array}$ \\
\hline 11 & $\begin{array}{l}\text { Polyimides } \\
\text { and } \\
\text { Bismaleimi-des }\end{array}$ & Structural & $\begin{array}{l}\text { Metals and } \\
\text { ceramics }\end{array}$ \\
\hline 12 & $\begin{array}{l}\text { Plastisols and } \\
\text { Elastosols }\end{array}$ & Non-structural & $\begin{array}{l}\text { Wide } \\
\text { ranging }\end{array}$ \\
\hline 13 & $\begin{array}{l}\text { Rubber } \\
\text { adhesives }\end{array}$ & Non-structural & $\begin{array}{l}\text { Wide } \\
\text { ranging }\end{array}$ \\
\hline 14 & $\begin{array}{l}\text { Solvent based } \\
\text { adhesives }\end{array}$ & Non-structural & $\begin{array}{l}\text { Wide } \\
\text { ranging }\end{array}$ \\
\hline 15 & $\begin{array}{l}\text { Water based } \\
\text { adhesives }\end{array}$ & Non-structural & $\begin{array}{l}\text { Porous } \\
\text { systems }\end{array}$ \\
\hline 16 & $\begin{array}{l}\text { Pressure } \\
\text { sensitive } \\
\text { adhesives }\end{array}$ & $\begin{array}{l}\text { Semi-structural } \\
\text { (susceptible } \\
\text { creep). }\end{array}$ & $\begin{array}{l}\text { Wide } \\
\text { ranging }\end{array}$ \\
\hline 17 & $\begin{array}{l}\text { Radiation- } \\
\text { cured adhesives }\end{array}$ & Can be structural & $\begin{array}{l}\text { Glass, } \\
\text { plastics and } \\
\text { ceramics. }\end{array}$ \\
\hline 18 & $\begin{array}{l}\text { Toughened } \\
\text { adhesives }\end{array}$ & Structural & $\begin{array}{l}\text { Wide } \\
\text { ranging }\end{array}$ \\
\hline
\end{tabular}

\subsection{Hardener}

Hardeners for epoxy resins are chemical compounds, which as a result of chemical reactions cause spatial crosslinking of resins and give them features of adhesive, sat rant or chemically-cured material. Hardeners used for curing epoxy resins can be divided into following groups:

i. Amine hardeners.

- Aliphatic amines

- Cycloaliphatic amines 
- Aromatic amines

- Adducts of aromatic and aliphatic amines and their modifications

ii. Polyamide hardeners.

iii. Amide hardeners.

iv. Anhydride hardeners.

v. Acids and bases of Levis type hardeners.

Choice of applicable hardener depends on type of resin, curing conditions and required properties of final product. In case of curing composition containing modifiers without epoxy groups, quantity of hardener should be referred to resin which is in composition. Before usage, resin should be mixed precisely with determined quantity of hardener. Curing process with amines is conducted at room temperature. On the basis of these factors, ARADUR $2963 \mathrm{CH}$ was chosen as the hardener for the specimen.

\section{Preparation of Specimen}

The properties for the selected materials, fabrication and cutting procedures of specimen, manufacturing challenges encountered are discussed in the further sections.

\subsection{Glass Fiber Cloth: 7 Mil E Glass}

- E-glass: alumino borosilicate glass

- Plain weave flat sheet

- Fiber orientation $0 / 90$

- Fiber diameter : 0.15-3.2 mm

- High strength to weight ratio

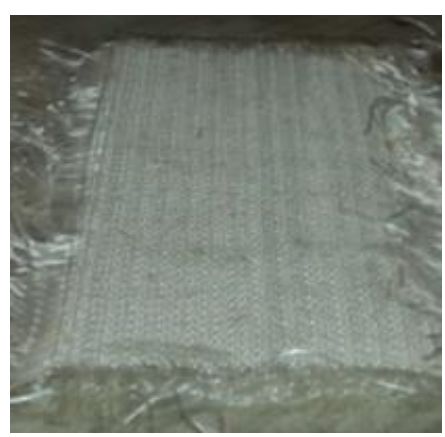

Fig 3.1 Glass Fiber Cloth

\subsection{Resin: Araldite 257}

Araldite 257 is a low viscose modified liquid epoxy resin based on Bisphenol A modified with aromatic glycidyl ether. Araldite GY 257 can be cured with polyamines, polyamidoamines or their adducts for solvent-free coatings, self-leveling and mortars floors, concrete injections, structure adhesives, trowelling compoundsand impregnationsystems.

\section{Properties}

- Resistant to chemicals (depending on the hardener).

- Resistance to crystallization.

- Shelf-life is longer as compared to Araldite -
LY 556

- Gel Time is 260-300 min.

- Very good processing properties

- Good mechanical performances.

- Good surface penetration.

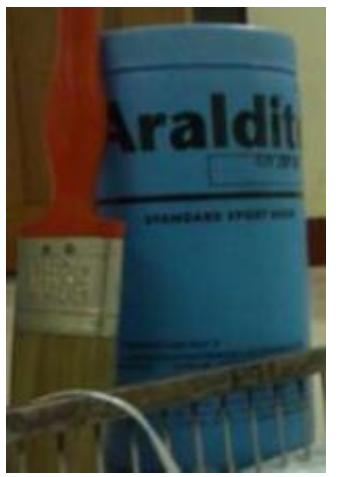

Fig 3.2.Epoxy Resin

\subsection{Hardener : Aradur 2963 Ch}

- Mixing ratio -100 parts by weight of the resin and $45+/-1$ parts by weight of the hardener.

- Light yellow clear liquid with amine-like odour.

- Stable under normal conditions

- Properties:

- Density is $1000 \mathrm{Kg} / \mathrm{m} 3$

- Boiling point is more than $200{ }^{\circ} \mathrm{C}$

- Flash point is $108^{0} \mathrm{C}$

- Kinematic viscosity is 30-70 MPa.s

- Composition:

- Isophorone diamine (30-42\%)

- Benzyl alcohol (30-42\%)

- Trimethyl hexamethylene diamine (5-11\%)

- 4.4 '-isopropylidene diphenol $(<5 \%)$

\subsection{Material Fabrication}

Selection of a method for fabrication of a particular part dependson the materials, the part design and end-use or application. The common methods for fiber based composites are sheet moulding, roll forming, pultrusion and hand layup methods.

Hand layup method is adopted for the fabrication of the $3 \mathrm{D}$ spacer fabric composite. It is a low volume, labour intensive method suited especially for the production of parts of any dimensions such as technical parts with a surface area of a few square feet.

\subsubsection{Procedure Of Fabrication}

1) Calculate the Glass fabric weight for the surface area desired.

2) Cut the spacer fabric material to the calculated weight.

3) Measure the quantity of resin equal to the weight of the fiber cloth.

4) Take hardener equal to $45 \%$ of the weight of the resin. 
5) Mix the resin and hardener together and stir continuously

6) Apply $40 \%$ of the mixture to mould and spread evenly.

7) Place the fabric on the mould and pour rest of mixture over it.

8) Roll gently for even distribution of the resin-hardener mixture throughout the fabric.

9) Allow the specimen to dry and harden.

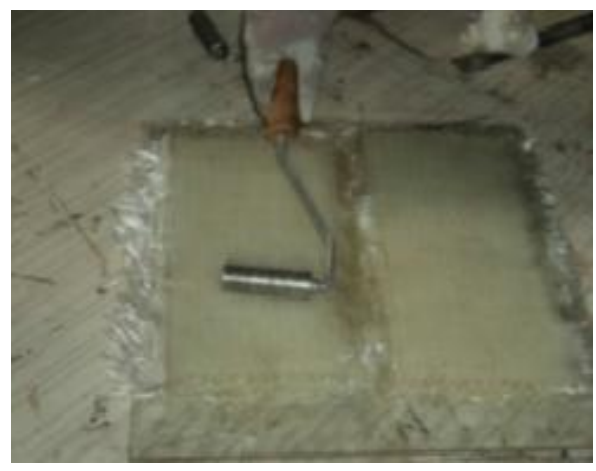

Fig.3.3 Hand Layup Fabrication

\subsection{Specimen Cutting}

After preparing of the specimen, proper cutting needs attention. Being three dimensional spacer fabrics composite and unlike sandwich having no coreproper attention to be taken to have smooth cutting without disturbing the yarnpiles. Water jet cutting gives a perfect and smooth cut to the sample and canavoid excessive force required for cutting other means like air jet cutting.Specimen cutting was performed according to ASTM standard-ASTM D 790for spacer fabric composite.

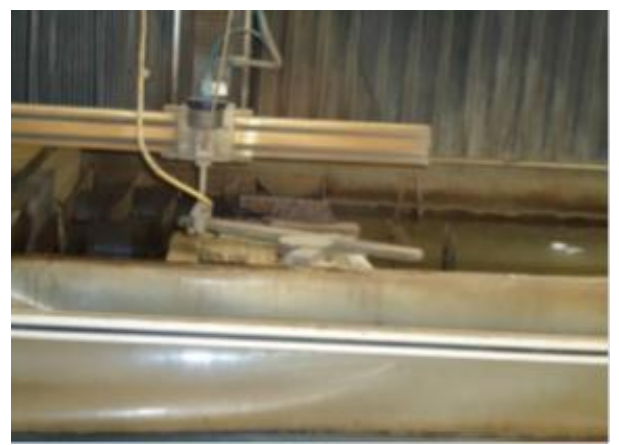

Fig. 3.4 A Water Jet Machine Showing Cutting Of A Specimen

\subsection{Joining the Panels}

The panels are joined in the project in various methods and configurations for the test. The joints are basically classified into 3 types such as Bonded Joint, Bolted Joint and Combined Joint. A total of 3 joint panels were made from the cut specimens. One bonded joint panel, one bolted joint and one combined joint panel. The joints adopted for the project are as follows:

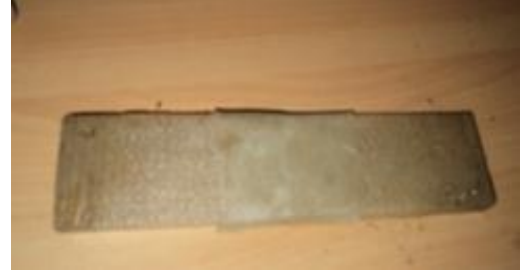

Fig.3.5.Bonded Joint

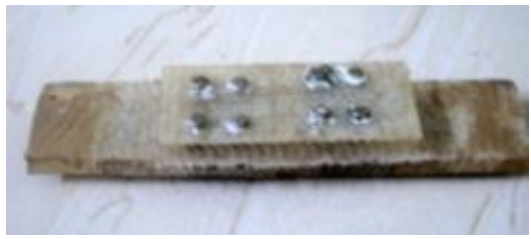

Fig.3.6.Bolted Joint

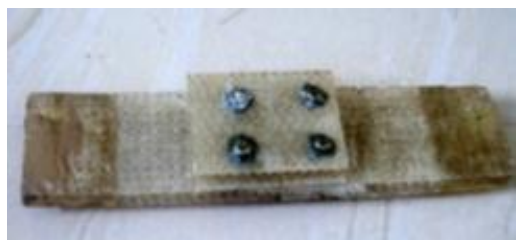

Fig.3.7Combined Joint

\subsection{Problems Encountered}

- Due to improper ratio of resin and hardener the specimen failed to stiffen properly.

- Minute Cracks developed during drilling.

- Specimens were very fragile for the UTM testing.

\subsection{Modifications Adopted}

- The fabric was reapplied with appropriate ratio of resin and hardener.

- Cracks were very minute, so neglected.

- For gripping the specimen ends were strengthened by resin and hardener.

\section{Testing Methodology}

After fabricating the required numbers of specimens, tests were carried out to investigate the behavior of the various groups of specimens when they were subjected to tensile tests. Tensile tests were conducted on the Universal Testing Machine by subjecting to load till failure. Properties that are directly measured via a tensile test are ultimate tensile strength, maximum elongation and reduction in area

\subsection{Experimental Setup}

A universal testing machine, also known as a universal tester is a materials testing machine or materials test frame, used to test the tensile stress and compressive strength of materials.

\section{- Specifications}

291 International Conference on Advances in Mechanical Sciences 2014 
- Capacity: $1000 \mathrm{kN}$

- $\quad$ Model : TUE-CN-1000

- Accuracy: +/- $1 \%$ in case of upper range

- Weight: $5100 \mathrm{~kg}$

- Power Supply : 3 Phase, 440V, 50 cycles AC

- $\quad$ Minimum test Speed : $0.01 \mathrm{~mm} / \mathrm{min}$

- $\quad$ Maximum test Speed: $500 \mathrm{~mm} / \mathrm{min}$

- Total Crosshead Travel: Preferably in the range of 1200-1400 mm

- Total Vertical Test Space: Preferably in the range of $1200 \mathrm{~mm}-1400 \mathrm{~mm}$

- $\quad$ Test Temperature: Room Temperature

- $\quad$ Test Humidity: Normal

- $\quad$ Micrometer type: Reading to $0.001 \mathrm{~mm}$ (0.00005 in)

- $\quad$ Caliper type Reading to $0.01 \mathrm{~mm}(0.0005 \mathrm{in})$

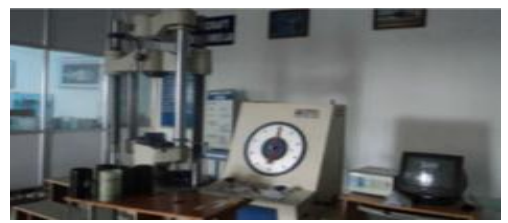

Fig.4.1 Universal Testing Machine Setup

\subsection{Testing Methodology}

- The specimen is mounted on the UTM and gripped tightly between the fixtures.

- Tensile load is applied hydraulically on the specimen and increased at a constant rate.

- Load is applied till the specimen fails.

Test is terminated at the failure of the material

- The Load vs. Displacement graph obtained from the test is studied forunderstanding the material behavior to the tensile load.

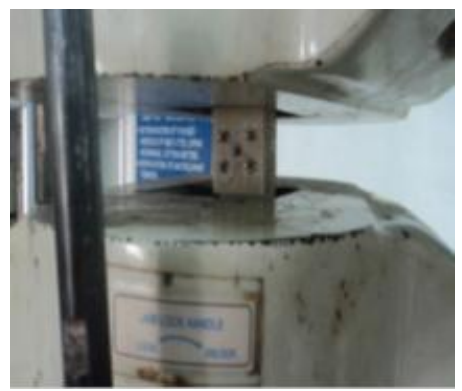

Fig.4.2 Specimen Mounted on UTM

The results of the tests yield the following data:

- Peak Load

- Tensile Stress

- Load at Yield

- Maximum Cross Head Travel

- Final Width and Thickness of Specimen

\subsection{Mathematical Computation}

For the mathematical Computation of Joint strength under tensile load, taken into consideration is the 4 bolted Single
Cover Butt Joint. By this method we derive the following values from calculation:

- Strength of the Joint

- Efficiency of the Joint

The formulas required for the calculations are attained from 'Design of Structures' by L.S.Negi.

A few assumptions are made to simplify complex analysis of joints which are as follows:

1) The tensile stress is uniformly distributed on portions of plate between the rivets.

2) The friction between the plates are neglected.

3) The shearing stress is uniformly distributed on the cross section of the rivets.

4) The bolts fill the hole completely.

5) The bolts in a group share the load equally.

6) Bending stress in the bolts is neglected.

If we consider the spacer fabric composite panels of length $100 \mathrm{~mm}$, width $60 \mathrm{~mm}$ and thickness $13 \mathrm{~mm}$ joined together by 4 bolt single cover butt joint. The bolt is designated as Mdxl-IS: 1363 is of diameter $5 \mathrm{~mm}$ placed at a pitch distance of $20 \mathrm{~mm}$. The allowable bearing strength and shear stress in bolt are $100 \mathrm{MPa}$ and $250 \mathrm{MPa}$ respectively, while the permissible tensilestress is $120 \mathrm{MPa}$.The tensile strength of the joint can be calculated using theunder given formulas.

1. Strength of plate between bolt holes in tension

$$
=\sigma_{\mathrm{at}} \mathrm{x}(\mathrm{p}-\mathrm{d}) \mathrm{xt}
$$

2. Rivet Value $=$ Smaller of bearing strength and shearing strength of rivet

- $\quad$ Bearing Strength of bolt $=\sigma_{\mathrm{pf}} \mathrm{x} \mathrm{dx} \mathrm{t}$

- $\quad$ Shearing strength of bolt $=\tau_{\mathrm{vf}} \mathrm{x}(\pi / 4) \mathrm{x}$ $d^{2}$

3. Strength of joint per pitch = smaller of:(i) the strength of plate between bolt holes in and (ii) rivet value

4. Strength of plate per pitch $=\sigma_{\text {at }} \times \mathrm{p} \mathrm{x} \mathrm{t}$

5. Efficiency of Joint=

Strength of joint per pitch $\times 100$

Strength of plate per pitch

Where,

$\sigma \mathrm{at}^{-}$allowable tensile stress in an axially loaded

tensionmember

$\sigma \mathrm{pf}^{-}$allowable bolt stress in member

$\tau_{\text {vf }}$ - allowable shear stress in bolts

$\mathrm{p}$ - Pitch

d- Effective diameter of bolt

T-Thickness of total plate

\section{Analysis of Experimental Data}

The appropriate analysis of the observations and obtaining the correct inference from the results and observations is the most important aspect of any experimental test.

The joint analysis can be done three different ways such as:

- Experimental

- Analytical

- Mathematical 
The graphs indicate the increasing tensile stress on the material and the joints with increased loads being applied. The plot begins from zero load and zero Cross head travel increasing linearly till the yield point is reached, where after there is a sudden drop in the values due to the failure of the material. Then the testing stops automatically or can be terminated manually.

From the results thus attained it is evident that the 8 bolt joint gives the highest valuefor the tensile strength of $8.14 \mathrm{~N} / \mathrm{mm} 2$. 4 bolted joint gave a tensile strength of $5.80 \mathrm{~N} / \mathrm{mm} 2$ and the resin bonded joint gave the lowest value of bonded joint strength of $3.29 \mathrm{~N} / \mathrm{mm}^{2}$ as shown in table.5.1.

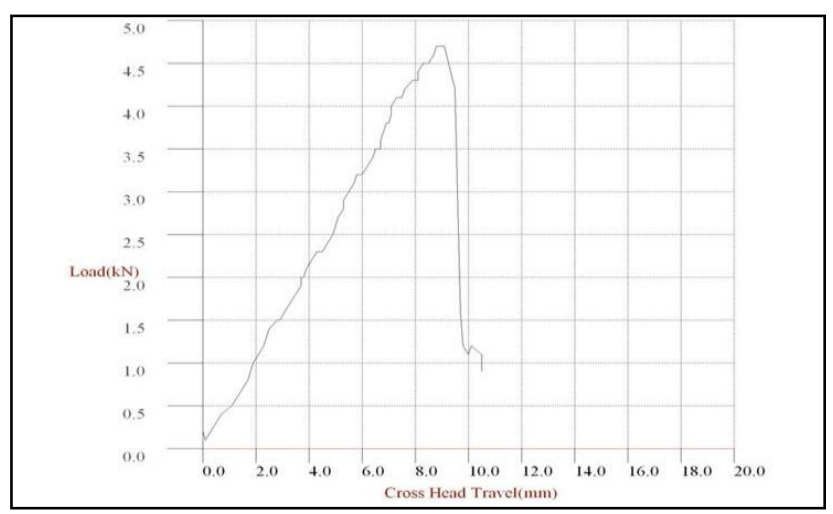

Fig.5.1 Graph for 4 bolt panel

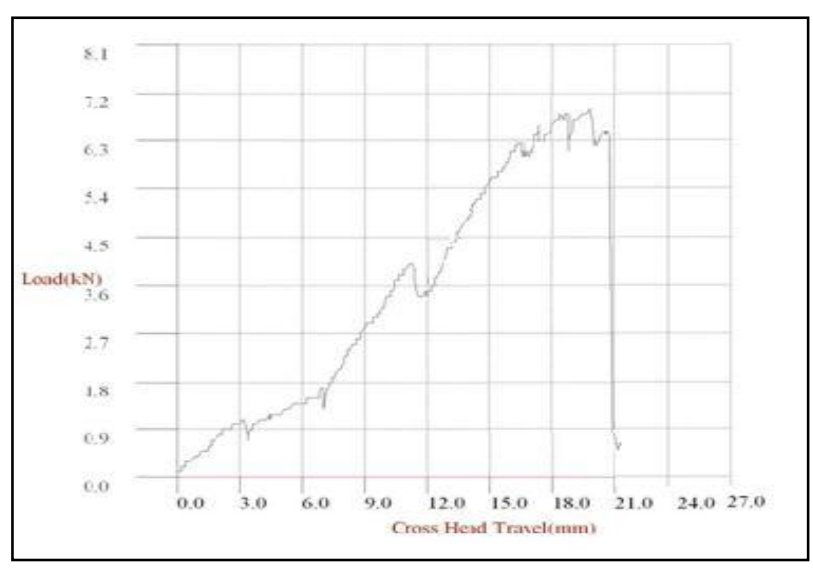

Fig.5.2 Graphical Result for 8 bolt Joint

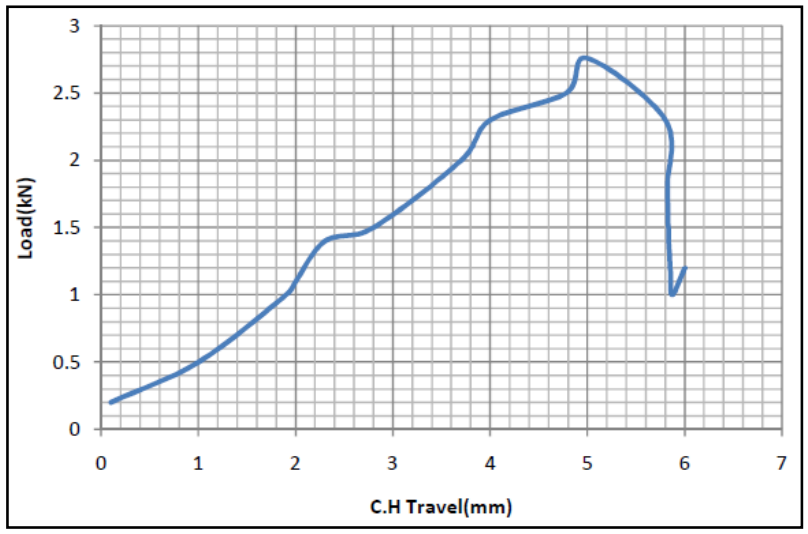

Fig.5.3 Graphical Result for Resin Bonded Joint

\subsection{Mathematical Results}

Table.5.1 Tensile Test Data

\begin{tabular}{|l|l|l|l|}
\hline Specifications & $\begin{array}{l}4 \text { Bolted } \\
\text { Joint }\end{array}$ & $\begin{array}{l}8 \text { Bolted } \\
\text { Joint }\end{array}$ & Resin Joint \\
\hline Peak Load(kN) & 4.7 & 6.60 & 2.76 \\
\hline Max. CH Travel $(\mathrm{mm})$ & 9.1 & 19.7 & 5.0 \\
\hline Load at Break $(\mathrm{kN})$ & 0.90 & .065 & 1 \\
\hline CH Travel at break $(\mathrm{mm})$ & 10.50 & 21 & 5.85 \\
\hline Tensile Strength $(\mathrm{N} / \mathrm{mm} 2)$ & 5.80 & 8.14 & 3.29 \\
\hline
\end{tabular}

In the previous section, the calculation formulae and method was discussed in detail. On application of the values of a four bolted single cover butt joint in the formulae have given the under given results.

- Strength of joint per pitch $=3.32 \mathrm{kN}$

- Strength of Plate per pitch $=3.24 \mathrm{kN}$

- Maximum strength of joint per pitch length $=6.6 \mathrm{kN}$

- Efficiency of joint $=67.5 \%$

The tensile strength of the joint attained experimentally for a 4 bolted butt joint is $5.80 \mathrm{~N} / \mathrm{mm} 2$ while attained mathematically is $6.6 \mathrm{kN}$.It is very evident that the results obtained are in good agreement with each other.

\subsection{Analytical Method}

The most daunting task of computing the adhesive joint strength was carried out by 'Adhesive Toolkit' by stress analysis on the resin bonded butt joint. The results thus generated from the stress analysis are as shown in the tables

Table 5.2 Results from Bonded Joint Test

\begin{tabular}{|l|l|l|l|l|}
\hline \multicolumn{5}{|l|}{ Table of Data } \\
\hline $\begin{array}{l}\text { Distanc } \\
\text { e } \\
(\mathrm{MM})\end{array}$ & $\begin{array}{l}\text { Shear Stress } \\
\text { Inner } \\
\text { Adherend } \\
(\mathrm{MPa})\end{array}$ & $\begin{array}{l}\text { Shear } \\
\text { Stress } \\
\text { Adhesive } \\
(\mathrm{MPa})\end{array}$ & $\begin{array}{l}\text { Shear } \\
\text { Strain } \\
\text { Adhesive } \\
(\%)\end{array}$ & $\begin{array}{l}\text { Shear } \\
\text { Stress } \\
\text { outer } \\
\text { Adherend } \\
(\mathrm{MPa})\end{array}$ \\
\hline 0.28 & 6.91 & 1.72 & 0.31 & 0.02 \\
\hline 0.69 & 6.81 & 1.67 & 0.3 & 0.06 \\
\hline 1.02 & 6.72 & 1.65 & 0.3 & 0.06 \\
\hline 1.52 & 6.59 & 1.61 & 0.29 & 0.12 \\
\hline 2.27 & 6.41 & 1.56 & 0.28 & 0.18 \\
\hline 3.39 & 6.15 & 1.48 & 0.27 & 0.26 \\
\hline 5.06 & 5.79 & 1.38 & 0.25 & 0.38 \\
\hline 7.55 & 5.30 & 1.23 & 0.22 & 0.54 \\
\hline 11.26 & 4.65 & 1.05 & 0.19 & 0.74 \\
\hline 16.80 & 3.87 & 0.84 & 0.15 & 0.99 \\
\hline 25.06 & 2.96 & 0.63 & 0.11 & 1.28 \\
\hline 34.95 & 2.12 & 0.48 & 0.09 & 1.55 \\
\hline 43.21 & 1.51 & 0.47 & 0.08 & 1.74 \\
\hline 48.74 & 1.09 & 0.52 & 0.09 & 1.87 \\
\hline 52.45 & 0.78 & 0.58 & 0.11 & 1.97 \\
\hline 54.94 & 0.55 & 0.64 & 0.12 & 2.04 \\
\hline 56.61 & 0.38 & 0.69 & 0.12 & 2.1 \\
\hline 57.73 & 0.26 & 0.72 & 0.13 & 2.14 \\
\hline 58.48 & 0.18 & 0.74 & 0.13 & 2.16 \\
\hline 58.98 & 0.12 & 0.76 & 0.14 & 2.18 \\
\hline 59.32 & 0.08 & 0.77 & 0.14 & 2.19 \\
\hline 59.73 & 0.03 & 0.69 & 0.12 & 2.21 \\
\hline
\end{tabular}


From the table 5.2, the maximum shear stress at the resin joint at tensile load application during yield is seen to be $2.21 \mathrm{kN}$. While the maximum shear stress of the adhesive is $0.69 \mathrm{MPa}$.The maximum shear strain percent of the adhesive is $0.31 \%$, but at maximum cross head travel it is $0.12 \%$.

From the experimental methods it is observed that the Maximum Strength of joint in the experimental method is at $2.76 \mathrm{kN}$ tensile loading which is similar to the results from the analytical method which gives maximum strength of $2.21 \mathrm{kN}$.Hence, it can be asserted that the results are in good agreement.

\section{Conclusion}

Bonding of discrete panels and joining of separately fabricated components are standard practice for composite structures. The strength of the adhesive bond is independent of the overlap for all but impractically short overlaps. Adhesives of highest strengths do not always produces the highest joint strengths. Ductility improves the load distribution by reducing stress peaking at the end of the joint. As the bonded joints are inherently weak, it is extremely important to minimize these adverse influences in the design and to make sure that the most critical condition is also accounted for in the design. The adhesive bonding is often the best way to permanently join composites to each other.

The original strength of a bolted joint section is actually reduced by increasing the number of bolted holes. At the weakest critical section, the number of bolt holes should be minimum for maximum efficiency. Though the bolted joint shows higher strength in comparison to bonded joints it has lower weight efficiency. Therefore it is very important to choose the bolts carefully for the material inconsideration. Also, it is important to choose the bolt design and joint types cautiously.

Using only three fundamental forces with the origin in the mechanical interlocking and interference, chemical reactions, and atomic level bonding, three fundamental options of mechanical joining, adhesive joining and combined joining emerge. Each has its advantages and disadvantages. Together with some variants of combinations these joints can provide remarkable diversity and capability.

\section{References}

A. Aggarwal, S. Ramakrishna and V. K. Ganesh,(2010), Predicting the In-plane Elastic Constants of Diamond Braided Composites, Journal of CompositeMaterials, vol.35, pp 665-688.

A.C. Manalo, T. Aravinthan, W. Karunasena,(2010),Flexural Behaviour of GlueLaminated Fibre Composite Sandwich Beams", Composite Structures, vol.92, pp 2703-2711.

Achim Menges, Integral Computational Design for Composite Spacer Fabric Structures, Stuttgart University, Germany.

Ahmet Refah Torun,(2011),Advanced manufacturing technology for 3D profiled woven performs, Technischen Universität Dresden.

Amit Yeole, (2006),Experimental Investigation and Analysis for Bearing Strength Behaviour of Composite Laminates, Shivaji University.

Anderson T.L,(1995)Fracture Mechanics: Fundametals and Applications, II Edition, CRC press, pp 44-46.

BoltedConnections,Lecture12,http://faculty.delhi.edu/hultendc/AECT250 Lecture\%2012.pdf
BoltedConnections,Lecture13,http://faculty.delhi.edu/hultendc/AECT250-

Lecture\%2013.pdfChangzhou Bolong Three Dimensional Composites. Co. Ltd,http://www.bolong3d.com/en/productshow.asp?classname=3D+spacer+fabri $\mathrm{c}+$ sandwich+composite

Composite Materials Handbook, (1999) MIL-HDBK-17, Vol 2, Chapter 2,

D. M. Hoyt, Stephen H. Ward and Pierre J. Minguet, (2002), Strength and Fatigue Life Modeling of Bonded Joints in Composite Structure, Journal of Composites Technology and Research.

D.M. Hoyt and Steve Ward,(2004),Composite Bonded Joints Analysis, Data, and Substantiation, Seattle.

Daniel. A, Marek. A and Krzysztof M, Composite Joints of Aerostructures,Transactions ofthe Institute Of Aviation No. 170-171

Diren Mecit, Arzu Marmarali,(2012), Application of spacer fabrics in composite production, Ege University, Izmir, Turkey.

Edward J. Hughes and John I, Rutherford,(1968),Study of Micromechanical Properties Of Adhesive Bonded Joints, New Jersey.

F.C Campbell,(2010), Structural Composite Materials.

G.M Lehman and A.V Havely, (1969) Investigation of Joints in Advanced Fibrous Composites for Aircraft Structures, Ohio, Technical Report AFFDL-TR-6943.

Geon-Woong Lee, Joong Sik Choi, Sang-Soo Lee, Min Park,(2003),Mechanical Properties and Failure Mechanism of the Polymer Composite with 3 Dimensionally Stitched Woven Fabric, Seoul, Korea.

Hong $\mathrm{Hu}$, Baozhong Sun, Hanjian Sun and Bohong Gu, (2010), A ComparativeStudy of the Impact Response of 3D Textile Composites and Aluminum Plates, Journal of Composite Materials, vol.44, pp 593-619.

Hong $\mathrm{Hu}$, Mingxing Zhang, Raul Fangueiro and Mario De Araujo,(2010), Mechanical Properties of Composite Materials Made of 3D Stitched Wovenknitted Preforms, Journal of Composite Materials, vol. 44,pp 1753-1767.

Introduction to connection Designs, Connection Designs, Static Loading, Lecture 11.1.2,

http://www.adhesivestoolkit.com/Introduction.xtphttp://www.fgg.unilj.si/kmk/esdep/master/wg11/10120.htm

J.C. Velosa, R. Fangueiro, F.W. J. van Hattum, F. Soutinho and S. Marques,(2010),Development of Reinforced Composite Sandwich Panels Based on 3D Fabrics, Budapest, Hungary.

J.R Vinson and Robert L.S,(2002), The Behaviour of Structures Composed ofComposite Materials, Kluwer Academic Publishers, chapter 4.

J.R Vinson et al,(1987), The Behavior of Structures Composed of CompositeMaterials, Kluwer Publications.

JA Soden, GFJ Stewart, D Campbell and A. McIlhagger, Manufacture and Testing Of 3d Woven Natural Fibre Composites.

Janetzko S,(2009), Development of Metal 3D Spacer Warp Knit Fabrics forthe Application of Hybrid Metal Plastic Products, 2nd World Conference on 3DFabrics and Their Applications, USA.

Joanne Yip and Sun-Pui Ng,(2008) Study of three-dimensional space fabrics:Physical and mechanical properties, Journal of Materials Processing Technology, Vol.206, Issues 1-3, pp- 359-364.

Kulak, G. L., Fisher, J. W. and Struik,(1987) J. H., A Guide to Design Criteria fo Bolted and Riveted Joints, 2nd ed. L.S.Negi,(2005), Designo Structures,TATAMcGrawhill,pp55

MD Banea, LFM da Silva, (2008), Adhesively bonded joints in composite materials:An Overview, Instituto de Engenharia Mecânica, Portugal.

Min Li, Shaokai Wang, Zuoguang Zhang and Boming Wu, (2009), Effect ofStructure on the Mechanical Behaviors of Three-Dimensional Spacer Fabric Composites. Appl Compos Mater, Vol.16, pp 1-14.

N. K. Naik, Sk. N. M. Azad and P. Durga Prasad, (2002) Stress and Failure Analysis of 3D Angle Interlock Woven Composites, Journal of Composite Materials, vol.36, pp93-123.

O. A. Khondker and I. Herszberg and K. H. Leong, (2001), An Investigation of the Structure-Property Relationship of Knitted Composites, Journal of CompositeMaterials, vol.35, pp 489-508.

Robert.R.Messeler, (2004), Joining of Materials and Structures: Pragmatic Process toEnabling Technology, Elseiver Butterman Heinemann Publications.

Shanna M. Bruer, (2005), Three Dimensional Knit Spacer Fabric, A Review of Production Techniques and Applications, Journal of Textile and Apparel, Volume 4 .

Shaokai Wang, Min Li, Yizhuo Gu, Zuoguang Zhang and Boming Wu,(2010),Mechanical Reinforcement of Three-Dimensional Spacer Fabric Composites. Materials Science Forum,Vol. - 654-656, pp 2604-2607.

Shaokai Wang, Min Li, Zuoguang Zhang and Boming Wu, (2010),Properties of Facesheet-reinforced 3-D Spacer Fabric Composites and the Integra Multifacesheet Structures, Journal of Reinforced Plastics and Composites, vol. 29, pp 793-806.

Suranga Gunavardhana,(2005), Prediction of failure initiation of Adhesively Bonded Joints using Mixed-Mode fracture Data.

U. Weerts and H. Kossira, (2000), Mixed Mode Fracture Characterization Of Adhesive Joints, ICAS, Germany.

Xiaocong He, (2010),Effect of Mechanical Properties of Adhesives on Stress Distributions in Structural Bonded Joints, London, UK, WCE, Vol II

Yo Co Chang Ltd.,http://www.ycglassfiber.com/3dcf/3dcf_01.php3D Glass Fabric Solutions, Parabeam,

3D Spacer Fabric,ppt FRP Services \& Co.(Shanghai) Ltd.http://www.parabeam.nl/site/page/processing_animation 